\title{
Apparent Modulus of Elasticity of Dental Amalgams
}

\author{
J. M. POWERS and J.W. FARAH \\ University of Michigan, School of Dentistry, Ann Arbor, Michigan 48104, USA
}

The modulus of elasticity of dental amalgam has been determined by analysis of creep data (OGLesby ET AL, J Res Natl Bur Stan 72C: 203, 1968) and by ultrasonic methods (DICKson and OGLEsBy, $J$ Dent Res 46: 1475, 1967; HALL ET AL, $J$ Dent Res 52: 390, 1973) to be between 63,000 and $70,000 \mathrm{MN} / \mathrm{m}^{2}$. These values represent the instantaneous elastic compliance term when dental amalgam is treated as a viscoelastic material. It is convenient, however, to approximate the behavior of dental amalgam as elastic in experimental stress analysis models. Thus, an apparent modulus of elasticity $\left(E^{\prime}\right)$ can be determined by measurement of the slope of a stress-strain curve in compression at a given loading rate. Values of $E^{\prime}$ determined in this manner for conventional dental amalgams at the one-week period were from 9,660 to $12,400 \mathrm{MN} / \mathrm{m}^{2}$ within a stress range from 34.5 to $172 \mathrm{MN} / \mathrm{m}^{2}$ at a loading rate of $0.008 \mathrm{~cm} / \mathrm{min}$ (TAYLOR ET AL, J Dent Res 28: $228,1949)$.

Values of $E^{\prime}$ and compressive strength $(S)$ were determined for five dental amalgams at 24-hour and one-month periods. Cylindrical specimens were prepared, using the procedure described in American Dental Association Specification no. 1 (Guide to Dental Materials and Devices, 1975),

Received for publication December 23, 1974

Accepted for publication February 17, 1975. from about $600 \mathrm{mg}$ of amalgam alloy following the manufacturers' recommended mercury-alloy ratios and trituration conditions. Specimens were loaded in compression to failure on a testing machine $e^{a}$ at a head speed of $0.020 \mathrm{~cm} / \mathrm{min}$. Deflection data were obtained from an optical

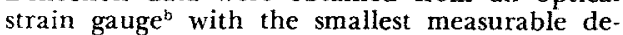
flection being 1.03 micrometers. $E^{\prime}$ was computed from the slope of the linear portion of a load-deflection curve with a correction made for the deflection of the steel plungers included within the gauge length.

Average values of $E^{\prime}$ and $S$ measured at 24hour and one-month periods are shown in the table. Scheffe intervals computed for the $95 \%$ level from analysis of variance were 5 and 1,800 $\mathrm{MN} / \mathrm{m}^{2}$ for horizontal comparisons of $S$ and $E^{\prime}$, respectively, and 13 and $4,600 \mathrm{MN} / \mathrm{m}^{2}$ for vertical comparisons of $S$ and $E^{\prime}$, respectively. For each amalgam except $C$, values of $E^{\prime}$ and $S$ were higher at the one-month period than at 24 hours. The amalgams containing copper as a major ingredient ( $D$ and $E$ ) had higher values of $E^{\prime}$ and $S$ at both times tested than the amalgams made from conventional $(A)$ and spherical $(B$ and $C)$ silver-tin alloys.

"Reihle, Wilson Instrument Division, Bridgeport, Conn.

b Tuckerman, American Instrument Co., Inc., Silver Spring, Md.

TABLE

Apparent Modulus and Compressive Strength of Dental Amalgams

\begin{tabular}{cccccc}
\hline & \multicolumn{2}{c}{$24-\mathrm{Hr}^{*}$} & & \multicolumn{2}{c}{$1 \mathrm{Mo}^{*}$} \\
\cline { 2 - 6 } Material & $\begin{array}{c}\text { Compressive } \\
\text { Strength }\end{array}$ & Modulus & & $\begin{array}{c}\text { Compressive } \\
\text { Strength }\end{array}$ & Modulus \\
\hline$A \dagger$ & $318(9)$ & $21,100(1,400)$ & & $346(13)$ & $24,100(3,700)$ \\
$B \ddagger$ & $344(6)$ & $18,900(940)$ & & $409(2)$ & $23,000(1,200)$ \\
$C \$$ & $367(7)$ & $24,100(3,900)$ & & $382(12)$ & $24,600(2,500)$ \\
$D \Uparrow$ & $423(14)$ & $34,000(5,100)$ & & $481(8)$ & $36,300(7,100)$ \\
$E \#$ & $483(13)$ & $31,300(3,400)$ & & $569(5)$ & $35,600(4,000)$ \\
\hline
\end{tabular}

- Units are $\mathrm{MN} / \mathrm{m}^{2}$. Means with standard deviations in parentheses were determined from five to eight replications.

+ New True Dentalloy (capsules), Lot No. 037403, S. S. White, Philadelphia, Pa.

†pher-a-Caps, Lot No. 1928, Kerr Sybron Corp., Romulus, Mich.

$\$$ Spherical Alloy Caps, Lot No. 12A72, L. D. Caulk Co., Milford, Det.

ff Dispersalloy (tablets), Lot No. 4A00I, Johnson \& Johnson, East Windsor, NJ.

\#Experimental alloy (powder), Lot No. R74831, Federal Mogul Corp., Ann Arbor, Mich; spherical particles with mean composition of $\mathrm{Ag}, 60 \% ; \mathrm{Sn}, 27 \%$; and $\mathrm{Cu}, 13 \%$. 